\title{
ENRIQUETA HUESO Y LA GALERÍA O+O (ORIENTE Y OCCIDENTE): UN ESPACIO ARTÍSTICO EN EL RELATO IDENTITARIO DE UN DISTRITO URBANO PERIFÉRICO

\author{
ENRIQUETA HUESO AND THE GALLERY O+O (ORIENTE AND OCCIDENTE):
} \\ AN ARTISTIC SPACE IN THE IDENTITY STORY OF A PERIPHERAL URBAN DISTRICT
}

Amparo Zacarés Pamblanco

Universitat Jaume I de Castellón

\section{RESUMEN}

La galería de arte valenciana es fundamentalmente de tipo urbano, ubicada en las tres capitales de provincia, en especial en la ciudad de Valencia. Se trata de una sociedad limitada o en régimen autónomo. En general, la ubicación de las galerías se da en zona comerciales cuyo estrato socialdemográfico tiene poder adquisitivo; sin embargo algunas se sitúan en entornos urbanos periféricos y ayudan a construir un relato reivindicativo ligado a la propia identidad cultural del barrio. A este tipo de galerías pertenece $\mathrm{O}+\mathrm{O}$ (Oriente más Occidente), que abrió la artista y galerista Enriqueta Hueso hace diez años en el barrio de Benimaclet de la ciudad de Valencia. El hecho de cumplirse una década de la inauguración de su galería y de que la trayectoria de su galerista esté suficientemente acreditada, es el motivo de este artículo.

Palabras Clave: mujeres artistas, galeristas, galerías de arte, gestión cultural, educación artística.

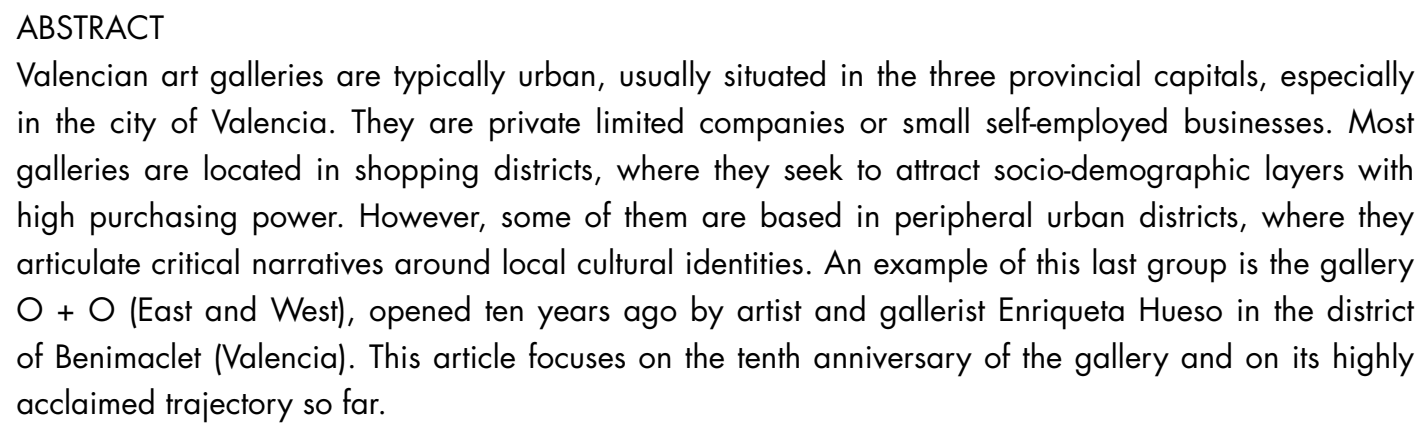

Valencian art galleries are typically urban, usually situated in the three provincial capitals, especially in the city of Valencia. They are private limited companies or small self-employed businesses. Most galleries are located in shopping districts, where they seek to attract socio-demographic layers with high purchasing power. However, some of them are based in peripheral urban districts, where they articulate critical narratives around local cultural identities. An example of this last group is the gallery $\mathrm{O}+\mathrm{O}$ (East and West), opened ten years ago by artist and gallerist Enriqueta Hueso in the district of Benimaclet (Valencia). This article focuses on the tenth anniversary of the gallery and on its highly acclaimed trajectory so far. 
Keywords: Women Artists, Gallery Ownwers/ Directors, Art Galleries, Cultural Management, Art Education.

\begin{abstract}
SUMARIO
1.- Las galerías de arte: un invento del siglo XIX en el panorama del siglo XXI. 2.- Empresas de gestión cultural. 3.- Enriqueta Hueso: artista y galerista. 4.- La Galería $O+O$ y la dinamización cultural de un distrito urbano periférico. 5. - Conclusiones.
\end{abstract}

\title{
1.- Las galerías de arte: un invento del siglo XIX en el panorama del siglo XXI
}

Durante mucho tiempo el concepto de galería de arte quedó vinculado a ser una tienda $\circ$ sala de exposiciones dedicada a vender objetos artísticos, fundamentalmente pictóricos o escultóricos. Su origen se remonta al siglo XIX, ante la necesidad de encontrar compradores para los cuadros de caballete. De este modo las galerías entraron en el mercado del arte, que empezaba a distanciarse de la producción por encargo y con ello comenzaron a regirse por la ley de la oferta y de la demanda. Además, las galerías fueron también un centro de intercambio para las vanguardias artísticas que a finales de aquel siglo surgieron en París. Artistas incomprendidos buscaron entonces otros lugares de exposición ajenos a los salones académicos que ni los consideraban ni los valoraban. En esa época para los pintores de moda siempre fue fácil vender directamente su obra: citaban a los compradores en su propia casa o en las de sus conocidos, con status social y poder adquisitivo, que solían vivir cerca de la Ópera. Fue en ese trasfondo socio-económico donde las galerías ofrecieron la única posibilidad de adquirir presencia y visibilidad a quienes aún eran desconocidos y que más tarde dejarían de serlo (Daumier, Corot, Cézanne, Gauguin o Van Gogh). Gracias a ello a principios del siglo XX y desde su primera mitad, grandes galeristas, como fueron Clovis Sagot, Berthe Weill, D.H. Kahnweiler, Leónce y Paul Rosenberg, Paul Guillame y Josse Hessell, apostaron por el arte contemporáneo.

En Nueva York, a partir de 1941, Peggy Guggenheim supuso un punto de inflexión y de impulso para el arte de vanguardia con el espacio Art of this Century patrocinado por ella misma, donde se concentraron los mayores marchantes del momento. Nueva York y París alcanzaron casi el mismo número de galerías en aquellos tiempos y sobresalieron como centros culturales con éxito. Aún así no hay que olvidar que también Los Ángeles, Chicago y San Francisco tuvieron un papel relevante al respecto. Y también, claro está, no puede dejar de nombrarse el papel que las galerías de Berlín, Milán y Londres desempeñaron en el comercio del arte. Por otra parte, quedaría incompleta esta referencia si no se recordara 
aquellas galerías que antes de la guerra civil española acogieron arte de vanguardia en Barcelona como las de Dalmau \& Rafel, la Sala Badrinas y Syra. Ya avanzada la segunda mitad del siglo XX, las galerías comenzaron a proliferar y se multiplicaron como espacio de intercambio y comercio y como centros dinámicos y potenciadores del arte declaradamente contemporáneo. Sus locales se ubicaron en las ciudades mencionadas, aunque la lista se amplió a Viena, Bruselas, Copenhague, Basilea, Berna y Haarlmen por citar las más significativas. Y en América, en concreto Sao Paulo, Buenos Aires y México, al igual que en Japón, especialmente en Tokyo, lugares que han despuntado en los últimos años dentro del mercado del arte y donde se han creado numerosas galerías.

Un panorama que da cuenta de la importancia y el peso de estas salas es el fenómeno conocido como comercialización del arte. De hecho, dentro de un capitalismo avanzado, el entramado del mundo del arte ha conformado un potente circuito mercantil y comunicativo en el que participan artistas, galerías, museos, coleccionistas y especialistas. En esta urdimbre cultural y comercial, las galerías aún sobresalen como punto de partida del fenómeno de la comercialización de la obra de arte. Resulta obvio que siguen siendo imprescindibles para sacar del anonimato al artista y atraer la atención sobre sus creaciones. Pero ya no siempre es así, en especial entre aquellos artistas que han comenzado a cortocircuitar el mismo proceso que comercializa con sus obras (Tompson, 2009:102). Son sólo unos cuántos -y se trata sobre todo de artistas ya consagrados, como Jeff Koons o Damien Hirst-, que en una atmósfera de cinismo post-artístico se han convertido en los propios negociadores de su obra y se han dedicado a mercantilizarla ellos mismos. En el caso Koons, éste reconoce no ser él mismo sino los operarios que contrata, quienes realizan la elaboración efectiva de las obras que él idea, y, en el caso de Hirst, ha terminado por tomar las riendas de la representatividad artística de sus obras en las subastas en las que ha participado. Quizás este devenir era el esperado en una cultura capitalista que reduce la obra de arte a su condición de mercancía sin aura a decir de Benjamin (1936), pero de ahí a deducir que la función de las galerías haya quedado caduca, hay un gran trecho, puesto que sólo quienes pueden permitirse provocaciones del tipo de las citadas, no necesitan usarlas como plataforma para publicitarse y dar a sus obras la apreciación de obra de arte. De nuevo hoy en el siglo XXI, con alguna diferencia de grado y forma, son artistas afamados quienes negocian con su obra por su cuenta a la manera de aquellos pintores de moda que en el XIX citaban en su casa a los posibles compradores.

Por ello, más allá del negocio artístico que las galerías sostienen, habría que considerarlas como espacios vivos que contribuyen al desarrollo de la vida social y cultural del entorno donde se ubican, con una proyección de menor a mayor intensidad. Desde este 
punto de vista, dejan de ser meros espacios documentales de aparición de la obra de arte, para convertirse en centros de dinamización cultural que tienden a potenciar la relación entre público y artistas emergentes. En este sentido, las galerías que apuestan por el arte de vanguardia nos permiten conocer en qué consiste el arte actual, que es lo mismo que decir que nos ayudan a comprender el mundo actual en su aparecer simbólico. En esta potencialidad de desvelarnos qué somos, y no en el precio que haya podido alcanzar una determinada pieza suficientemente publicitada para que el negocio prosiga, es donde radica el papel valioso de las galerías artísticas que, en la mayoría de los casos, están dirigidas por quienes conocen el carácter trascendental de la creatividad humana en un determinado momento de una cultura concreta.

\section{2.- Empresas de gestión cultural}

Tras este bosquejo inicial, conviene no perder de vista la importancia de las galerías de arte como empresas de gestión cultural. En este sentido, se hace preciso definir el concepto de gestión como una actividad empresarial que contiene un variado número de funciones como son el aprovisionamiento de los bienes o productos que se precisan para llevar a cabo un programa de actuación, la financiación de dicho programa así como los recursos humanos o personal necesario para realizarlo. Junto a ello, la función de marketing o comercialización se presenta como básica para acercar la obra al público y darla a conocer. Finalmente, toda gestión se cierra con un análisis sobre los resultados alcanzados con la venta y sobre la comunicación con el público, con el fin de orientar y mejorar producciones posteriores.

De todos modos, el hecho de ser empresas de gestión dentro del ámbito de la cultura exige plantearse qué se entiende por cultura. Desde luego existe una primera apreciación antropológico- sociológica que entiende por cultura el modo, las costumbres y el estilo de vida de una población. Pero también se da una concepción clásico-humanista que define la cultura como la manifestación artística, creativa e intelectual de la humanidad. Las galerías de arte se centran en esta segunda acepción y consideran la gestión desde la perspectiva económica que asume la cultura como el conjunto de actividades artísticas. De hecho, el concepto de galería de arte que se asume en general como recoge Martínez Tormo (2014: 118 ) es la de ser:

Todo establecimiento abierto al público, de explotación privada, cuya actividad principal es la exposición y el comercio de obras de arte, y que se dedica también, en mayor o menor medida, a estimular la creación y a promover el arte, los artistas y su creación. En este sentido, se estima que, al menos, el $85 \%$ del total de facturación debe resultar del comercio de la obra de arte. 
Entendidas de esta forma, las galerías hacen posible que los artistas puedan sacar adelante sus proyectos y que los espectadores puedan satisfacer sus necesidades relacionadas con la sensibilidad artística. Sin embargo, muchos no están conformes en relacionar gestión económica y cultura, considerando incompatible marketing y producción artística. Estas voces críticas argumentan que la gestión pertenece al ámbito de los negocios y que está dirigida a la lógica y a los intereses materiales del mercado mientras que las artes están vinculadas a intereses espirituales centrados en la producción misma de la obra. Por el contrario, otros aducen que son compatibles ambos campos:

Aquellos que nos dedicamos a la investigación y estudio del sector cultural desde disciplinas económicas, así como muchos profesionales del sector consideramos que, además de que ambos mundos son perfectamente compatibles, la gestión en el ámbito cultural, y en concreto el marketing, debe perseguir un equilibrio entre la orientación al mercado y la orientación al producto, entre la satisfacción del espectador y la creación del artista. El objetivo final, y centrados en el ámbito de los que hemos denominado servicios culturales, no es otro que conseguir una audiencia (atraer espectadores a una sala), hacerla fiel (conseguir que vuelvan en otra ocasión), conseguir su implicación (que no sólo sean asistentes sino amigos de la institución) y estimularla (perseguir que participen aportando fondos o ayuda), tal y como señala Kotler (1980). Todo ello permitirá tanto el desarrollo libre de la creación artística, la satisfacción de las necesidades de los consumidores de actividades culturales, como alcanzar los objetivos organizativos por parte de las entidades productores o programadoras de dichas actividades (Cuadrado, 2013: 20).

De hecho, esta compatibilidad entre gestión y cultura ha ampliado el sector cultural a múltiples manifestaciones y entidades: museos, galerías de arte, cines, teatros, centros culturales, salas de concierto, librerías, bibliotecas, auditorios, casas de cultura y asociaciones culturales. Así, al tiempo que la democratización de la cultura se extendió, la misma gestión cultural se hizo más compleja. No es aquí el momento de analizar pormenorizadamente esta complejidad, que requeriría de un estudio más preciso y profundo, pero sí cabe señalar algunos aspectos de su evolución para comprender mejor cómo ocurrió.

Fue a partir de la década de los 80, momento en el que se produce la eclosión cultural en España tras los años de dictadura, cuando se crean numerosos museos, auditorios y centros culturales de titularidad tanto pública como privada. En los 90 comienza la profesionalización de la gestión cultural y, en consecuencia, se programa un considerable número de seminarios y masters impartidos sobre todo por diputaciones y universidades. En la siguiente década, a principios del siglo XXI, se concentran los primeros congresos en gestión de artes y de cultura emitidos tanto por las administraciones públicas como por las universidades. Tras 
esta evolución que acontece en toda España con sus características diferenciales según qué ciudad, destaca Valencia como lugar que presenta una gran oferta y dinamización cultural aún a pesar de los recortes acontecidos por la crisis económica (Cuadrado, 2013: 25).

Desde esta perspectiva, ya de lleno en la segunda década de este milenio, la pregunta por la gestión cultural en el sector de las galerías de arte valencianas ha de centrarse en especial en los cambios que ha padecido el mundo comercial del arte en el entorno de la misma Comunidad Valenciana. Al respecto, tanto el cierre como la reconversión de profesionales que desarrollaban su actividad en las galerías, provocaron un impacto negativo en la difusión de la cultura. Pero precisamente por ello no hay que incidir solo en los aspectos económicos que se consiguen o no en torno a las exposiciones, sino que conviene valorar las galerías de arte como agentes socio-culturales intermediarios del arte. $Y$ es en ese sentido en el que se plantearon a nivel nacional varios estudios donde, junto al censo y la clasificación de las galerías, se incluyeron encuestas cualitativas diseñadas ex profeso para conocer las motivaciones de galeristas mediante la realización de entrevistas personalizadas y otros instrumentos metodológicos procedentes de las ciencias sociales.

Estos estudios tienen su precedente a nivel nacional con la investigación impulsada por la Unión de Asociaciones de Galerías de Arte en España (1995), a la que siguieron a nivel autonómico las realizadas por diversas entidades como el Observatorio Vasco de la Cultura (2010) o la Generalitat de Catalunya (2011). En cuanto a la Comunidad Valenciana, se recabó información de diversas fuentes: Registro Estatal de Galerías de Arte Moderno y Contemporáneo del Ministerio de Educación, Cultura y Deportes; la Asociación de Galerías de Arte de la Comunidad Valenciana (AGACOVA) y el servicio de información municipal del Ayuntamiento de Valencia. Los resultados del censo dieron una distribución territorial de las galerías en las que sobresalía Valencia (51) frente a Alicante (13) y Castellón (4). A la ciudad de Valencia le corresponden 47 galerías, frente a las 9 en la ciudad de Alicante y a las 4 de la ciudad de Castellón (Martínez Tormo, 2014: 117).

De este modo se constata que la galería de arte valenciana es fundamentalmente de tipo urbano, ubicada en capitales de provincia, en especial en la misma ciudad de Valencia y constituida como una sociedad limitada o en régimen autónomo. Ahora bien, más allá de consideraciones relacionadas con la ubicación de las galerías, que dan que pensar en una estrategia empresarial planificada en la búsqueda de zona comerciales cuyo estrato socialdemográfico tenga poder adquisitivo, cabe analizar las posibilidades que ofrecen las galerías de arte situadas en entornos urbano periféricos para construir un relato reivindicativo ligado a la propia identidad cultural del barrio. En este caso se trata de galerías que contribuyen a la formación de un público que valora satisfactoriamente la experiencia artística para 
su desarrollo social y humano y que rompe con el tópico de que el arte es solo para una minoría que puede pagarlo. A este tipo de galerías pertenece la galería $\mathrm{O}+\mathrm{O}$ (Oriente más Occidente) que abrió la artista y galerista Enriqueta Hueso hace diez años en el barrio de Benimaclet de la ciudad de Valencia. El hecho de cumplirse una década de la inauguración de su galería y de que su trayectoria como galerista esté suficientemente acreditada, es el motivo de este artículo. Su galería, a lo largo de estos años, ha ganado importancia entre la población del barrio que la frecuenta no sólo para ver o sentir un objeto artístico sino para participar de forma psíquica y activa en la recepción del arte contemporáneo. De ahí que el espacio cultural creado por Enriqueta Hueso sea algo más que una plataforma de difusión para la obra de los y las artistas que exponen en sala, demostrando interés en marcar su carácter de actor social-dinámico dentro de un entorno urbano periférico que promueve la cultura y la inclusión social.

\section{3.- Enriqueta Hueso: artista y galerista}

Desde que Linda Nochlin (1971), la inventora de los estudios de género, se preguntara por qué no había habido grandes mujeres artistas y por qué la historia del arte había excluido de «la calidad artística» a todo aquello que no seguía el canon androcéntrico establecido, se hizo evidente que ser mujer y artista llevaba un plus añadido de dificultad del que no se hablaba. Siguiendo su estela, las Guerrilla Girls comenzaron a denunciar, a mediados de los ochenta del siglo pasado, la discriminación que las mujeres sufrían en los museos y en las galerías de arte. Con sus acciones visibilizaron que en las galerías comerciales más conocidas de Nueva York menos del 10\% de las obras expuestas, o absolutamente ninguna, eran de mujeres artistas y también que en 1985 ninguna mujer artista había realizado una exposición individual en el Guggenheim, en el Metropolitan o en el Whitney y tan sólo una en la Tate Modern. Durante siglos los museos han estado llenos de arte hecho por hombres. Una denuncia que Guerrilla Girls continúan en la actualidad, enfatizando el arte realizado por mujeres y promoviendo más recientemente campañas contra la violencia de género y la desigualdad.

Este panorama no distaba mucho del que se encontró Enriqueta Hueso (Valencia, 1948) que a lo largo de su vida profesional ha tenido que conciliar ser artista y galerista. Nace en Valencia y realiza estudios de dibujo, escultura y pintura en la Escuela de Artes y Oficios de Valencia y de Bellas Artes en la Universidad Politécnica de Valencia, completa el curso de Adaptación Pedagógica del Instituto de Ciencias de la Educación de la misma ciudad y termina sus estudios en la Facultad de Bellas Artes, en la Especialidad de Grabado, 
de Sevilla. Según en qué momento tuvo que decantarse por una u otra faceta, aunque también podría decirse que es una galerista artista, ya que aquí el término artista funciona no como adjetivo sino como sustantivo, pues ser artista no puede ser en ella un apéndice o un adorno sino su trasfondo básico, que se percibe de inmediato tanto en su trato personal como en la gestión profesional de su galería. De hecho puede definirse como una artista multidisciplinar por excelencia que ha forjado a fuerza de voluntad y talento creativo un prolífico curriculum relacionado con el mundo de la cultura y del arte.

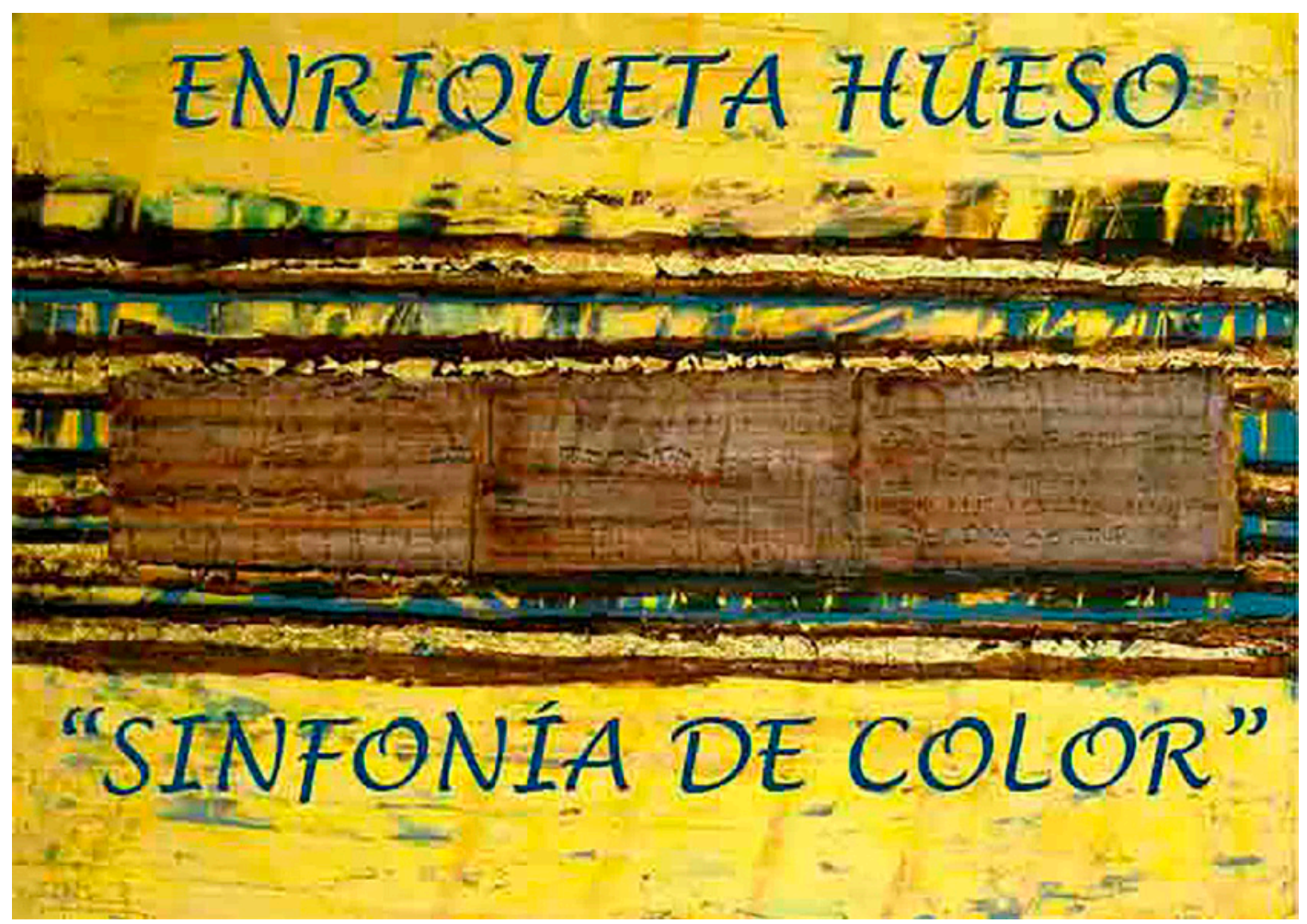

Cartel publicitario de la exposición de la artista Enriqueta Hueso, en el MKAC Museo Karura Art Centre's. Fuente: WordPress (2010).

Si algo le caracteriza es su capacidad polifacética para dirigir y coordinar proyectos, debates, mesas redondas y actividades artísticas dispares. Como artista participará con

Dossiers Feministes, 23, 2018, 169-184 - ISSN: $1139-1219$ - DOI: http://dx.doi.org/10.6035/Dossiers.2018.23.10 
su obra en numerosas exposiciones, tanto a nivel nacional como internacional, de las que cabe reseñar en España (Interarte, Arte Sevilla, MKAC, Feria Estampa Madrid) en Holanda (Holland Art Fair \& International Art Contemporany Rotterdam Fair), Alemania (International Fair of Book's Art and Paint \& Impulse International Fair of Osnabruck), Suiza (Nederlans Congres Centrum \& International Fair Europart), Nueva York (Feria de Artexpo), Italia (Feria Agrigento Sicilia), China ( XI Edition Art Fair Shanghai). A estas podría añadirse una extensa lista que pasa por Tokyo, Taiwan, Seúl, París, Madrid y Roma.

Desde 1985 compagina su labor creativa con la función de conferenciante y docente sin dejar de seguir ampliando su formación en el campo de la cinematografía, la fotografía y la psicología. Su capacidad de compromiso social y su vertiente más solidaria le llevan a organizar la exposición «30 mujeres por el pueblo cubano», donde reúne la obra de escultoras, pintoras y fotógrafas. Fue una exposición que la Asociación José Martí le planteó para recabar fondos destinados a los hospitales cubanos; se realizó en el Instituto de la Mujer y logró el fin que se proponía al venderse todo. Pero no fue solo en esta ocasión cuando Enriqueta Hueso se preocupó por dar visibilidad a las mujeres artistas, ya que en toda su trayectoria de gestión cultural las sitúa en primera línea de cartel, como en los conciertos que organiza con Alicia Alcaide (clavecín) y Carmen Masqués (soprano) sobre música del siglo XVIII o bien con Eva Denia (cantante de jazz) en la sala Rialto, o cuando reúne en una mesa redonda sobre mujeres escritoras a Fina Cardona, Maria Fullana y Charo Altable. Además, a requerimiento de varias escritoras, realiza las portadas e ilustraciones para sus libros. Diseña el logotipo, portada e ilustraciones de algunos libros de la Editorial Derzet i Dagó y colabora con Crátera. Revista de Crítica y Poesía Contemporánea para las ilustraciones de sus colecciones de literatura y poesía.

Enriqueta Hueso Martínez es también Diplomada en la Especialidad de Psiquiatría por la Facultad de Medicina de Valencia y posee un amplio currículo en la formación continuada del personal de Enfermería. Su preocupación por temáticas feministas le lleva a participar en diversos medios en defensa del derecho al aborto (TVE, Radio Nacional de España). Colabora en tertulias con Lydia Falcón y se suscribe a su revista Vindicación Feminista. Realiza un Curso de Cine Feminista en la Universidad Menéndez Pelayo y centra su interés durante una época en el análisis del rol de las mujeres en el cine. Su pasión cinéfila, que va desde el cine clásico de Hollywood hasta el independiente europeo y americano, le motivan a realizar cursos de cine de autor impartidos por Mar Busquets. Demostró un gran talento en este arte y en 1995 gana el premio al mejor guion de cine en la Universidad Literaria de Valencia con el cortometraje, que dirige y rueda ese mismo año, titulado: Los medios me vuelven loca. 
Varios especialistas avalan la calidad artística de sus obra plástica como son Román de La Calle (Univèrsitat de València), Joan Feliu (Universitat Jaume I de Castellón) u Hortensia Mínguez (Universidad Ciudad Juárez México). En líneas generales, su pintura combina el color y lo matérico hasta lograr composiciones que revalorizan formas concéntricas, el punto y la espiral, con una gran fuerza expresiva. Así aparece en sus series dedicadas a la flora, el paisaje y la música, tal como queda reflejado en «Pentagrama azul», «Caracolas» O «Juego de dominó» entre otras. Finalmente, lo más reciente hasta la fecha es haber sido artista seleccionada en la IV bienal internacional de arte de Caudete que se celebrará de octubre a noviembre en $2017^{1}$. En resumen, toda su obra está unida a su deseo por entender la realidad y la vida desde la experiencia perceptiva, pero su dilatada actividad artística, de la que se ha hecho solo un breve semblante, no ha oscurecido su faceta como galerista, donde ha demostrado tener grandes dotes para la gestión cultural.

\section{4.- Galería O+O y la dinamización cultural de un distrito urbano periférico}

Su tendencia a interrelacionar campos artísticos diversos (pintura, grabado, fotografía, videoarte, moda, diseño de potadas de libros, anagramas, logotipos, carteles) le lleva a crear en 2007 la galería O+O (Oriente más Occidente) ${ }^{2}$. Se trata de una galería ubicada en Benimaclet que es el nombre que recibe el distrito número 14 de la ciudad de Valencia. Originariamente Benimaclet fue un municipio independiente hasta 1878, año en que el que pasó a ser una pedanía, pero fue en 1972 cuando se integró en la ciudad como distrito y con el tiempo ha conseguido destacar por ser un barrio urbano reivindicativo muy comprometido con la cultura y la integración social. No es casual que el actual distrito de Benimaclet englobe el antiguo pueblo y las zonas urbanizadas de su alrededor, así como la zona en la que se encuentra localizada la Universidad Politécnica de Valencia que se conoce como Campus de Vera. Al pertenecer la Facultad de Bellas Artes al distrito universitario de la Universidad Politécnica, Beniclamet acoge la residencia de gran número de estudiantes y muchos artistas tienen localizado su taller o estudio en esta zona. La galería $\mathrm{O}+\mathrm{O}$ es pues una galería alejada del centro de la ciudad, situada en la periferia pero arraigada en el barrio citado tras una década de presencia y funcionamiento.

Por otra parte, el nombre O+O (Oriente más Occidente) no es casual, pues responde a la motivación por interconectar la visión artística de ambas miradas. De este modo Enriqueta 
Hueso compagina la gestión cultural y el comisariado intercultural de carácter internacional, siendo referente y pionera del intercambio entre Oriente y Occidente, proyectando tanto las creaciones de artistas del mundo occidental al mundo asiático y viceversa.

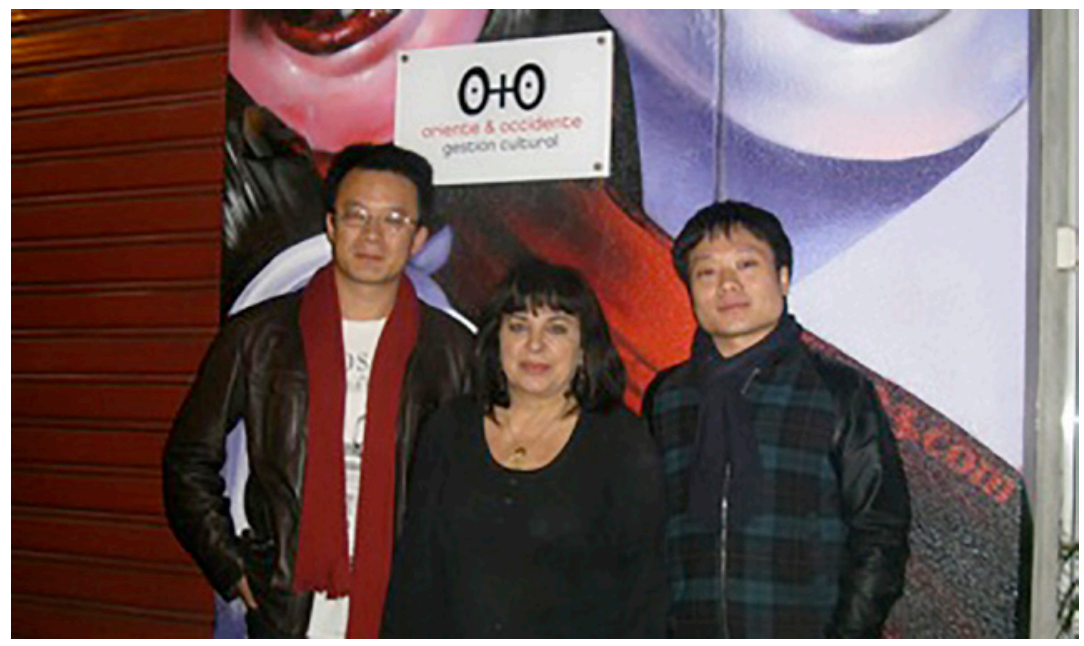

Enriqueta Hueso, Jia Yonsheng y Luo Jialin en 2010.

En el que sería el cuarto aniversario de la galería, Enriqueta Hueso anunció la apertura de su nueva sede en Pekín, que llevaría el mismo nombre que en España, asentando de este modo la promoción y divulgación del arte chino en Occidente al igual que el arte español en Oriente. A tal fin se une al equipo chino formado por Jia Yonsheg y Luo Jialin, formados en Bellas Artes y diseño. Este sería solo el principio, porque la proyección internacional de su labor cultural recibió a partir de entonces numerosos reconocimientos. Conviene no olvidar que llevará también al mismo recinto de la galería, ubicada en el barrio de Benimaclet, la pintura del Kenryo Hara (Japón), de Hu Youben (China/Pekín) y Bibek Santra (India). El punto de inflexión fue sin embargo en 2011, año en el que dará a conocer internacionalmente este barrio con exposiciones de 35 orientales del grupo internacional Tsai Mo (China).

En 2012, junto a Pilar Palomares, prepara una instalación para la Feria Estampa 2012 en Madrid, que titulan: «Spanish revolution-La guerra silenciosa». Se trata de un panel que denuncia la especulación y la crisis y que sitúa a Sánchez Gordillo en icono protagónico de la actualidad de esos momentos. La galería $\bigcirc+O$ es premiada como stand y la misma instalación se expuso después en New York. Valga la siguiente cita para subrayar el reconocimiento profesional que Enriqueta Hueso concitó como galerista: 
Con el montaje de «Spanish revolution-La guerra silenciosa» queda patente que el arte siempre ha estado cercano a lo social, junto con su función principal de lanzamiento de artistas. De hecho, el ejemplo de ello es que en Estampa el «stand» de ORIENTE Y OCCIDENTE (O O) ha tenido una gran asistencia habiendo sido además reconocido por la propia dirección de la feria, junto con el aplauso del público y de la crítica. Y es que observando la obra de artistas como Inés Ranseyer, Pilar Palomares o Sergio Belinchón, no cabe la menor duda de que la galería de Enriqueta Hueso sigue en la línea de calidad a que tiene acostumbrado al sector, demostrando año tras año su buen hacer y profesionalidad, manteniendo, además, como ha quedado demostrado en la recién concluida edición, criterios que son muy favorables a la colaboración social.

Logró, en definitiva, la galería $O$ + $O$ este año en Estampa, a través del inspirado e inspirador panel, una forma de testimoniar de la manera más sublime la palmaria realidad que nos asola. $Y$, además, como no podía ser de otra forma, dicha galería, que, como se ve, tiene un par de Oes, a cargo de Enriqueta Hueso (coautora con Pilar Palomares de «Spanish revolutionLa guerra silenciosa»), ha recibido el premio de la Asociación Madrileña de Críticos de Arte (AMCA) a la mejor galería de la Feria Estampa Arte Múltiple 2012, ante lo que ya solo nos queda dar la enhorabuena a las dos artífices del proyecto por ser elegantemente plásticas sin perder, eso sí, ni un ápice de irreverencia (Vadillo, 2012).

La Gestión Cultural $\mathrm{O}+\mathrm{O}$ se convierte a partir de entonces en un centro de referencia internacional; su idea, que se gesta a partir de distintas culturas plásticas entre Oriente y Occidente, consigue realizar un intercambio cultural encaminado hacia la difusión del arte y la cultura, así como la promoción artística de los artistas y sus obras. Las exposiciones que presenta son tanto individuales como colectivas; se cuentan como un logro, donde las fronteras y las separaciones se confunden, en pos de la unicidad creativa. Enriqueta Hueso aparece como una galerista que conoce bien a sus artistas, que los cuida y los anima en su trayectoria emergente no exenta de dificultades. Son un número elevado, pero, a modo de ejemplo, cabe citar a Inés Ramseyer, Renato Manzoni, Manolo Sáez, Pilar Monleón, Antonio Pardines, Xavier Raventós, Pilar Palomares, Daniel Despothuis, Monique Thomas, Albert Castellanos o Albert Sesma. Este último rememora el trato humano que demuestra como galerista al afrontar la vulnerabilidad de sus representados y representadas, siendo capaz de sacar al mismo tiempo su mayor potencial creativo. En definitiva, Albert Sesma glosa la labor de Enriqueta Hueso, como una forma de estar cercana y sensible, distanciada en consecuencia de una gestión fría y abstracta, agradeciendo su función de mediadora entre el espectador y el artista. Sus palabras, a modo de poema visual, resultan ser un revelador testimonio ${ }^{3}$ : 
La labor de enlace.

La labor de representar.

La labor de hacer crecer.

La labor de una Galería de Arte.

La labor de una Galerista. Ella es artista.

La labor de alguien quien cree en alguien.

La labor de persona que trata con persona.

La labor de Alguien llamada Enriqueta Hueso

En 2014, dos años después del éxito de Feria Estampa en Madrid, la Salomon Arts Gallery de Nueva York abrió sus puertas a la exposición que organizaba junto a la Galería de Arte de Valencia O+O. Enriqueta Hueso presenta para esa ocasión la obra fotográfica de Inés Ramseyer, el trabajo artístico de Pascual Bort, las creaciones de Luis González Boix, los paisajes de Juan Carlos Julián y las fotografías de Paco Sancho. Y a ella misma la presentan como la galerista que ha dedicado su vida a la solidaridad y el arte:

Enriqueta Hueso, la galerista española quien llegó a Nueva York con las obras de arte a cuestas, la energía del que cree en lo que hace y el amor de quien conoce a cada uno de los artistas como si fueran su familia, empieza a hablar con voz pausada y nos cuenta con sencillez y honestidad las esperanzas que encierra una exposición en Nueva York. Conoce la calidad y la dedicación de sus artistas y está feliz de poder presentarlos en la prestigiosa galería de Gigi y Rodrigo Salomón para que los conozcan en una ciudad como Nueva York donde se concentra lo mejor del arte a nivel internacional (Bafile, 2014).

Volviendo a la Galería $\mathrm{O}+\mathrm{O}$, como centro que ha hecho posible el diálogo entre el arte de Occidente y Oriente, en su dilatada trayectoria internacional, Enriqueta Hueso no ha olvidado en ningún momento el entorno urbano donde está situada su galería, contribuyendo a la dinamización cultural dentro de Benimaclet, organizando cursos de pintura y de caligrafía china, participando con la asociación de vecinos del barrio en concursos de pintura al aire libre o de videoarte, dando a conocer el arte y la cultura oriental y con ello contribuyendo a potenciar la interculturalidad en un barrio cada vez más multicultural. Son sus mismos vecinos y sus mismas vecinas quienes le agradecen su empeño en potenciar culturalmente el barrio. Gratitud que culminó con la concesión del Premio de la Asociación de Vecinos y cuyo reconocimiento queda plasmado en las sentidas palabras que pronunció su presidente ${ }^{4}$ :

4 Testimonio de Antonio Pérez, Presidente AV Benimaclet, Discurso en la entrega de la distinción a los héroes y heroínas del barrio, envidado por correo electrónico, 9/X/2017 
Para nosotros, sus vecinos y amigos, una de las cosas más importantes que ha hecho Enriqueta Hueso hacia el barrio es la creación de una galería de arte en Benimaclet. Hubiera sido más fácil y más rentable instalarse en el centro de Valencia, donde se centran la mayor parte de galerías de arte, pero su amor al barrio ha hecho posible una nueva aventura artística y comercial, que esperamos le sea beneficiosa en todas sus partes, tanto económicamente como artísticamente, y por eso se merece todo nuestro respeto y nuestro apoyo. Según la RAE, la definición de héroes es "persona ilustre y famosa por sus hazañas o virtudes», pero hay muchas otras personas a nuestro alrededor que nos demuestran día a día que son los verdaderos héroes anónimos sin tener ninguna notoriedad pública. Enriqueta Hueso es una de esas heroínas, que tienen siempre una voluntad de servir, no de servirse, y se muestran ante nosotros como verdaderas heroínas.

\section{4.- Conclusiones}

Los testimonios de agradecimiento y de reconocimiento tanto a la calidad humana como a la profesionalidad de su gestión cultural, arraigada durante una década en el barrio de Benimaclet, hace plausible deducir que la galería $O+O$ sigue la estela del mandato de la UNESCO en su Carta de Ciudades Educadoras (2013). En ella se impulsa a las ciudades y a sus entornos urbanos (barrios, distritos) a desarrollar su potencial educador abriendo locales, en especial en espacios públicos, donde las personas puedan acceder libremente a la cultura y aprendan a participar, a convivir y a ejercer la ciudadanía. Es cierto que las galerías de arte, como sociedades limitadas o en régimen autónomo, son de gestión privada pero no cabe duda que admiten el acceso al público transeúnte y que su presencia sirve de motivación cultural en las inmediaciones donde se ubican.

En ese sentido, conviene reivindicar la gestión dinamizadora de la Galería $\mathrm{O}+\mathrm{O}$, como un espacio no formal de sensibilización y educación artística que ayuda a la transformación social. De hecho, varios de los compromisos que recomienda la Declaración de Beijing sobre la creación de Ciudades del Aprendizaje, pueden encontrarse en Benimaclet a tenor de la labor cultural que se lleva a cabo en el propio barrio desde la misma asociación de vecinos. Se planifican actuaciones tendentes a empoderar a las personas y promover la cohesión social, a fomentar una cultura de aprendizaje a lo largo de toda la vida o impulsar la movilización y utilización de los recursos. Puede aducirse que estos planteamientos deben ser impulsados sobre todo por políticas públicas, desde entidades o instituciones gestionadas por los gobiernos locales, pero siendo esto así no impide valorar a ciertas entidades privadas que llegan a consolidarse como nuevas configuraciones urbanas potenciadoras de la cultura, la educación y la participación ciudadana. 
A esta tendencia de promover la prosperidad cultural del hábitat urbano, se ajusta la gestión galerista de Enriqueta Hueso. No hay que olvidar que en las zonas de la ciudad donde hay más ingresos, las personas que viven allí tienen mayores oportunidades para acceder a la cultura de primera mano. El hecho de que la galería $O+O$ se haya asentado en un barrio que no destaca por tener altos ingresos, supone de por sí velar por la protección e integración de personas y grupos en situación vulnerable. La clave reside en promocionar el arte y la cultura, dentro de un encuadre inclusivo en lo comunitario, en combinación con la necesidad de proyectar la venta de la obra artística. Y estos objetivos, tras diez años de presencia activa en el barrio, se han conseguido con creces.

Si bien todas las galerías pueden ejercer de locales de dinamización cultural, no todas lo hacen en los mismos términos, ni todas están diseñadas como herramientas de compensación y de redistribución social de la cultura. Depende de la intencionalidad con la que se incorporen a la planificación territorial de la ciudad y que funcionen como espacios de educación artística no formal, con el fin de mejorar las posibilidades del aprendizaje cultural de las personas. El espacio artístico creado por Enriqueta Hueso en Benimaclet corresponde a ese tipo de galerías donde el arte contemporáneo contribuye a construir las relaciones humanas dentro del entorno urbano.

Hoy, cuando cada vez se tiene mayor posibilidad de acceso virtual a los objetos culturales, un número considerable de personas se interesan por frecuentar personalmente espacios culturales, y en esa tendencia se incluyen las galerías como salas de exposiciones. Esa fruición estética entre el sujeto y el objeto artístico, propia de un público cada vez más participativo, es esencial para el desarrollo y la formación de la sensibilidad humana (Aguilar, 2012). Siempre ha sido una ventaja el que para entrar en contacto directo con las obras de arte no fuera necesario ni tener un gran poder adquisitivo ni de movilidad. Y esa ventaja es la que ha regalado Enriqueta Hueso a Benimaclet, potenciando culturalmente el barrio urbano donde hace una década decidió abrir su galería. Su historia es pues la crónica de una mujer inmersa en la gestión cultural de las galerías de arte, campo en el que aún hay que seguir indagando para dar visibilidad a tantas mujeres que se han dedicado a ser gestoras de proyectos expositivos artísticos. En definitiva, este artículo pretende contribuir a este fin, valorando el esfuerzo y el grado de implicación de una galerista de proyección internacional que ha sido pionera en acercar el arte entre Oriente y Occidente. 


\section{5.- Bibliografía}

Agullar, Guadalupe (2012). El arte participativo, Ayuntamiento de Culiacán - México: Ensayo. BAflLE, Mariza (2014). «Enriqueta Hueso: una vida dedicada a la solidaridad y al arte», Viceversa Magazine. Recuperado de http://www.viceversa-mag.com/enriquetahueso-entrevista (Fecha de consulta 10/11/2017).

BeNJAMIN, Walter (1973). «La obra de arte en la época de su reproductibilidad técnica». En Discursos interrumpidos - I, Madrid: Taurus.

CUADRADO, Manuel (2013). «La gestión artístico-cultural en el contexto valenciano contemporáneo» en DE LA CAllE, Román (coord.) (2013). Los últimos 30 años del arte contemporáneo valenciano (II), Valencia: Real Academia de Bellas Artes de San Carlos.

Generaltat De Catalunya (2011). Estadística de galeries d'art. (2003-2009).

Martínez Tormo, José (2014). «La gestión de las galerías de arte en la Comunidad Valenciana» en De LA CALLE, Román (coord.) (2014). En torno a los últimos 30 años del arte valenciano contemporáneo (I), Valencia, Real Academia de Bellas Artes de San Carlos.

NochuIN, Linda (1971) «Why Have There Been No Great Women Artists?» en NochuN, Linda (1988). Women, Art, and Power and Other Essays, London: Thames \& Hudson.

Observatorio Vasco De Cultura (2010). Kultura 08-09. Gobierno de Euskadi

Organización de las Naciones Unidas Para la Educación y la Cultura (Unesco) (2013). Declaración de Beijing sobre la Creación de Ciudades de Aprendizaje. Recuperado de file://es-red-mundial-de-ciudades-del-aprendizaje-de-la-unesco-documentos-guia. pdf (fecha de consulta: 8/11/2017).

THOMPSON, Don (2009). El tiburón de 12 millones de dólares, Madrid: Ariel.

VADILLO, Antonio (2013). «La ignominia ha pinchado en Hueso». Recuperado de http:// centiartgallery.blogspot.com.es/2013/02/ (Fecha de consulta: 10/11/2017).

VVAA (1995). Las galerías de arte en España. Informe encargado por la Unión de Asociaciones de Galerías de Arte de España. 